\title{
Odor recognition without identification
}

\author{
Anne M. Cleary, Kristen E. Konkel, Jason S. Nomi, and David P. MCCabe \\ Colorado State University, Fort Collins, Colorado
}

\begin{abstract}
Odors are notoriously difficult to identify, yet an odor can often lead to a sense of recognition, despite an inability to identify it. In the present study, we examined this phenomenon using the recognition-withoutidentification paradigm. Participants studied either odor names alone or odor names that were accompanied by scratch-and-sniff stickers containing their corresponding scents. At test, the participants were presented with blank scratch-and-sniff stickers, half of which corresponded to items that were studied and half of which did not. The participants attempted to identify each test odor, as well as to rate the likelihood that it corresponded to a studied item. In addition, the participants indicated whether they were in a tip-of-the-tongue (TOT) state for a given odor's name. Odor recognition without identification was found, but only when the participants had actually smelled the test odor at study; it was not found when the participants only studied odor names and were then tested with odors, suggesting that this effect is an episode-specific, perceptually driven phenomenon. Despite this difference, an overall TOT-attribution effect, whereby recognition ratings were higher during TOT states than during non-TOT states, was shown across conditions.
\end{abstract}

Odors are notoriously difficult to identify (e.g., Cain, 1979; Herz \& Engen, 1996). People are much poorer at naming odors (e.g., strawberry) than at naming their visual referents (e.g., a picture of a strawberry; Stevenson, Case, \& Mahmut, 2007). Despite this, people often experience a feeling of recognizing an odor without being able to identify it. This phenomenon has sometimes been referred to as the "tip-of-the-nose" experience (e.g., Herz \& Engen, 1996; Lawless \& Engen, 1977; Schab, 1991). In the present study, we attempted to investigate this phenomenon using a new methodology. Specifically, we created an odor variation of a common laboratory method of inducing recognition without identification (RWI).

In the laboratory, RWI is the finding that participants can discriminate old from new items on a recognition test even when the test items' identification is hindered (e.g., Cleary \& Greene, 2000). Said differently, participants can recognize a test item as having been experienced earlier in the experiment, despite an inability to identify the experimental episode responsible for the sense of recognition. In the present study, we investigated whether this empirical RWI phenomenon would occur with odors and, if so, whether it would involve existing semantic knowledge of odors and their names or whether it would instead be an episode-specific, perceptually driven phenomenon.

\section{Memory for Odors and Their Names}

Odors have a peculiar relationship with verbal labels in human memory. On one hand, there is ample evidence that verbal labeling can actually influence odor perception (e.g., Djordjevic et al., 2008; Herz, 2003; Herz \& von Clef, 2001). On the other hand, how odors function as a component of semantic memory is not well understood (e.g., Cain, de Wijk, Lulejian, Schiet, \& See, 1998), and as was mentioned above, odors tend to be difficult to identify. Although there is a general consensus on this latter point (e.g., Herz \& Engen, 1996), there is not a general consensus as to why. Some have suggested that weak connections between odors and their names in semantic memory are to blame (e.g., Stevenson \& Case, 2005; Stevenson et al., 2007); others have suggested that lack of access to the source of the odor itself (rather than a mere lack of access to its name) may be the problem (Jönsson, Tchekhova, Lönner, \& Olsson, 2005).

Stevenson et al. (2007) reported evidence that odor names (e.g., the name strawberry) and their odor referents (e.g., the smell of strawberry) are more weakly linked in semantic memory than the same names and their visual referents (e.g., an image of a strawberry). Although some prior research suggests that odor imagery involves representations of the actual odors themselves (e.g., Djordjevic, Zatorre, Petrides, \& Jones-Gotman, 2004), Stevenson et al. demonstrated that names more easily induced imagery of their visual referents (e.g., an image of a strawberry) than of their odor referents (e.g., the imagined smell of a strawberry). Furthermore, in line with prior research (see Herz \& Engen, 1996, or Schab, 1991, for a review), Stevenson et al. demonstrated that whereas visual images (e.g., an image of a strawberry) are easily named, odors (e.g., the smell of strawberry) are not as easily named.

The evidence that odors and their names are mutually ineffective cues for each other's retrieval raises the question of what type of information produces the feeling of recognizing an odor that cannot be identified. One possibility is 
that the feeling of recognizing an odor without identifying it (sometimes termed the "tip of the nose" experience; Herz \& Engen, 1996; Lawless \& Engen, 1977; Schab, 1991) is simply the standard tip-of-the-tongue (TOT) experience. In a TOT experience, a person has a feeling of knowing that a word is in memory, despite an inability to access the word at that moment (e.g., Brown, 1991; Gollan \& Brown, 2006; Rastle \& Burke, 1996; Schwartz, 2002). Although many theories assume that there is an attributional or inferential basis for TOT experiences (e.g., see Schwartz, 2002, for a review), some theories assume that the TOT experience involves preexisting connections between semantic and phonological information and the inaccessible target (e.g., Gollan \& Brown, 2006; Rastle \& Burke, 1996).

Although the ability to recognize an odor that cannot be named may seem similar to the standard TOT experience, Lawless and Engen (1977) presented evidence that the two operate differently. Whereas people experiencing a standard TOT state often have access to partial information about the target word itself, such as its first letter, what it sounds like, or its number of syllables (e.g., Brown, 1991; Rastle \& Burke, 1996), people experiencing a so-called tip-of-the-nose state do not. Instead, they may have access to qualitative information about the odor itself but not to information about its name (see Herz \& Engen, 1996, for a review). Jönsson and Olsson (2003) more recently replicated the finding that participants do not access partial information during tip-of-the-nose states. They further showed that participants had very little, if any, consciously reportable knowledge regarding the source of the odor during these states.

That people have difficulty accessing even partial information about an odor's name in response to the odor itself is consistent with the idea that odors and their names are weakly connected in semantic memory. It is also consistent with the idea that odors are weakly connected to all information relevant to specifying the source of the odor, and not just to their names (Jönsson et al., 2005). In either case, it follows that even partial information about an odor name would be difficult to access in response to an odor.

Given the evidence that odor names and their referents are weakly linked in semantic memory, what type of information drives instances in which one has a sense of recognizing an odor without identifying it (i.e., the aforementioned tip-of-the-nose phenomenon)? It is theoretically possible that this phenomenon (hereafter referred to as odor RWI) can involve the preexisting link between a familiar odor and its name in memory, even when the name itself is inaccessible. In models of memory for other types of names and their referents (such as for people's names and their faces), the preexisting link in memory can lead to a feeling of familiarity with the referent (i.e., a person's face) even when the referent's name (i.e., the person's name) is inaccessible (e.g., Burton, Bruce, \& Hancock, 1999). However, if the link between odors and their names is indeed weaker than that between other types of referents and their names in memory, it is also possible that this link is not involved in odor RWI. Instead, such odor recognition may be a form of perceptually driven memory: It may be driven by sensory aspects of the smell itself rather than by the activation of the name in response to the smell. In support of this latter possibility, Jönsson et al. (2005) reported that feelings-of-knowing (FOKs) for odors were correlated with the familiarity of the odors themselves.

\section{The Laboratory-Based RWI Effect}

A promising methodology for investigating the aforementioned issues related to odor recognition is that which is used for the laboratory-based RWI effect. Peynircioğlu (1990) reported the earliest experimental demonstration of laboratory-based RWI effect. Participants studied a list of words (e.g., RAINDROP, AMETHYST) and were then given a test list containing word fragments. Half of the fragments came from studied words (e.g., $\mathrm{R}_{-}{ }_{-} \mathrm{ND}_{-}{ }_{-} \mathrm{P}$ ) and half came from nonstudied words. The participants attempted to identify the word corresponding to a given fragment and also rated the likelihood that the fragment came from a studied word. RWI is shown in this paradigm by the fact that, among unidentified fragments, recognition ratings discriminate those that correspond to studied words from those that do not. This specific effect has been replicated numerous times (e.g., Cleary, 2002; Cleary \& Greene, 2000, 2001) and has been extended to many stimulus types, including picture fragments (Cleary, Langley, \& Seiler, 2004), auditory word fragments (Cleary, Winfield, \& Kostic, 2007), and song fragments (Kostic $\&$ Cleary, 2009). It has also been shown when auditory word identification is hindered by embedding the spoken words in white noise (Cleary et al., 2007), when song identification is hindered by isolating song rhythm or tonal information (Kostic \& Cleary, 2009), and when word or picture identification is hindered through the use of perceptual identification tasks in which the stimuli are rapidly flashed and masked (e.g., Arndt, Lee, \& Flora, 2008; Cleary \& Greene, 2004, 2005; Langley, Cleary, Kostic, \& Woods, 2008).

Whereas some forms of RWI are influenced by semantic memory (i.e., preexisting knowledge; Cleary, 2006; Cleary \& Reyes, 2009; Cleary \& Specker, 2007), other forms are dependent on episode-specific perceptual information (Arndt et al., 2008; Langley et al., 2008). Thus, the RWI paradigm may be particularly well suited for an investigation of whether odor RWI can involve preexisting links between familiar odors and their names or whether it is instead a perceptually driven form of memory.

Evidence for the influence of semantic memory on RWI comes from studies showing that it occurs when names are studied and their referents (e.g., pictures of the items that had only been named at study) are presented and unidentifiable at test. Semantic memory must influence RWI performance in these cases, because there is no overlap between the episode-specific perceptual information from study (e.g., a word's presentation) and that occurring at test (e.g., a picture's presentation).

An example of such a form of RWI is the face RWI effect shown by Cleary and Specker (2007). Cleary and Specker presented names of celebrities at study. At test, participants were presented with pictures of celebrities' 
faces, half of whose names had been presented at study and half of whose names had not been presented at study. For each celebrity face presented at test, the participants were asked to name the person. Even when the celebrity could not be named, the participants were asked to rate the likelihood that the person's name had been studied. RWI in this case was shown by the fact that, among celebrity faces that could not be named (identified) at test, the participants' familiarity ratings still discriminated between faces of celebrities whose names were studied and faces of celebrities whose names were not studied. Cleary and Reyes (2009) demonstrated the same phenomenon with famous scenes (e.g., Taj Mahal, Sistine Chapel). Among test scenes that went unidentified, participants could discriminate between those whose names were studied and those whose names were not studied.

Although the results of Cleary and Specker (2007) and Cleary and Reyes (2009) suggest that some forms of RWI can involve preexperimental knowledge about names and their referents, other forms of RWI appear to involve episode-specific perceptual representations. For example, Langley et al. (2008) demonstrated that RWI for unidentified black-and-white line drawings (e.g., a hammer) in a perceptual identification task only occurred when the rapidly flashed test drawings themselves had actually appeared at study; it did not occur when only the names of the drawings (e.g., the word hammer) or other exemplars of the depicted objects (e.g., a drawing of a different kind of hammer than that presented at test) had appeared at study. Furthermore, Arndt et al. (2008) found RWI for nonwords (which do not have preexisting semantic representations). That some forms of RWI involve existing semantic knowledge linking names to their referents, whereas others are primarily driven by the reinstatement of studied perceptual information at the time of test, makes the RWI paradigm particularly well suited for investigating the question of whether odor RWI may be a perceptually specific form of memory.

The purpose of the present study was threefold. First, we examined whether the RWI phenomenon can be shown with odors that cannot be identified at test. Although the RWI phenomenon has been shown in many modalities, it has not yet been shown with odors. Second, we examined whether the odor RWI effect involves preexisting connections between odor names and their referents, or whether it is among the perceptually specific types of RWI. Specifically, we examined whether odor RWI can occur when only odor names are studied and the referents (i.e., the odors themselves) are presented at test or whether odor RWI requires reinstatement of the studied odors at the time of test. Given that Jönsson et al. (2005) found some support for the idea that the familiarity of an odor cue itself may be related to the reported FOK for that odor, it is plausible that familiarizing an odor through prior presentation on a study list will lead to an odor RWI effect, but merely presenting the names of the odors at study will not.

Finally, in the present study, we also examined TOT states for odor names in response to odors at test. Previous research on the TOT phenomenon has suggested that TOT states for odor names differ from TOT states for other types of information (Lawless \& Engen, 1977) and that TOT states are rarer for odor names than for people's names (Jönsson et al., 2005). Previous research with the RWI paradigm has shown that participants attribute the presence of a TOT state to the likelihood that an inaccessible name was studied (Cleary, 2006; Cleary \& Reyes, 2009; Cleary \& Specker, 2007). This pattern occurs despite the common finding that studying a word or name does not increase the likelihood of a reported TOT state for that inaccessible word or name at test (Cleary, 2006; Cleary \& Reyes, 2009; Cleary \& Specker, 2007; Rastle \& Burke, 1996). In the present study, we examined whether the same would be true of TOT states for odors. That is, even though TOT states for odors are thought to differ from TOT states for other types of information (e.g., Jönsson et al., 2005; Lawless \& Engen, 1977), would participants still attribute being in a TOT state for an odor's name to its having been studied?

\section{METHOD}

\section{Participants}

Sixty-eight Colorado State University students participated in exchange for payment.

\section{Materials}

The stimulus pool consisted of 80 different scents and their corresponding names (see the Appendix for the full list of scents used in the present study). Eighty different scents per participant had been printed via microencapsulation on blank, clear, circular stickers (commonly known as scratch-and-sniff stickers). The stickers were each $3 / 4$ in. in diameter and were purchased for use in the experiment from Print-A-Scent (a company that specializes in microencapsulation).

Each participant received a booklet containing all of the experimental materials. Each booklet was a $6 \times 4$ in. two-ring binder that held one hundred twenty $6 \times 4$ in. unruled index cards; one stimulus trial was presented per index card. The booklets were divided into two study-test blocks, with 20 study cards appearing before 40 recognition test cards in each block. Assignment of stimuli to block, as well as the presentation order within the study and test phases, was randomized for each participant. Which items were studied was counterbalanced across participants. In addition, $4 \times 6$ in. sheets of paper with typewritten instructions appeared prior to each phase in the booklet.

The index cards created for the study phase fell into one of two conditions. In one condition (the name-only condition), only the names of scents were presented at study; in this condition, each name was typewritten in 16-point Times New Roman font in capital letters on a white printing label and placed toward the top center of its card. In the other condition (the name-plus-scent condition), the names were presented in the same manner as in the first condition, but in addition, beneath each name was the clear scratchand-sniff sticker containing the scent corresponding to that name. Each card in the test phase contained a single clear scratch-andsniff sticker in the center of the card unaccompanied by the scent's name. Half of the test scents corresponded to studied cards, and half did not; the test scents were presented in a randomized order for each participant. The bottom left-hand corner of each test card contained a space for writing the test scent's name that said, "Smell name? _. Below that space was a space for rating the likelihood that the scent (or its name) had been studied. This section stated, "Rating from $0-10(0=$ definitely not studied; $10=$ definitely studied): ___ . The bottom right-hand corner of each test card contained a space for indicating the presence or absence of a TOT state. This part said, "Are you in a TOT state for the smell's name? (yes or no?) 
Throughout the experiment, the participants had access to toothpicks for use in scratching at the stickers to release their encapsulated scents and to a container of coffee beans to smell in between smelling each sticker, since empirical evidence supports the common notion that this technique works for cleansing the nasal palate (Secundo \& Sobel, 2006).

\section{Procedure}

The participants were run in groups of 4-8. After all of the participants had completed a consent form, the booklets were distributed to them. The participants were randomly assigned to either the name-only study condition or the name-plus-scent study condition. In addition, which stimuli were studied was counterbalanced across participants; hence, there were four versions of the booklets altogether, and the participants were each randomly assigned to one of these versions.

Upon receiving a booklet, the participants began the experiment by opening the booklet and reading the first page, which contained typewritten instructions on how to proceed. In the name-only condition, the participants were given the following instructions:

This experiment will consist of 2 study-test blocks. At study, you will be presented with 20 names of specific scents. For each smell name on the study list, please try to imagine the actual smell (e.g., if the word is "incense" try to imagine what incense smells like).

In the name-plus-scent condition, they were given these instructions:

This experiment will consist of 2 study-test blocks. At study, you will be presented with 20 scratch-and-sniff stickers of specific scents, along with the names of the scents. For each item on the study list, please scratch each sticker with the given toothpick and try to remember each smell and its name.

In both conditions, the participants were then instructed as to the nature of the memory test that would follow the study list. They were told that they would be presented with scents at test, half of which were studied (or had had their names studied) and half of which were not studied. They would then be asked to attempt to identify each scent on the test and also to rate the likelihood that the scent (or its name) was studied and to indicate for each scent whether they were experiencing a TOT state for the scent's name. Following from prior studies of TOT experiences (e.g., Cleary, 2006; Cleary \& Reyes, 2009; Cleary \& Specker, 2007; Schwartz, 2001), a TOT state was defined in the following way:

A TOT state is when you feel as if you could recall the smell name, and recall of the name feels imminent. It is as if the name is on the "tip of your tongue," about to be recalled, but you simply cannot think of the word at the moment.

The participants were also instructed that once they turned a page in the booklet, they could not flip back to earlier pages and that the experimenter would be watching to make sure that no one did that.

Upon finishing the typewritten instructions, each participant then flipped through the 20 study-list cards at his or her own pace; there was no formal time limit for each page, but the participants were aware that the entire experiment would end after $1 \mathrm{~h}$, and were given reminders regarding the time. In the name-only condition, the participants simply read each scent name and attempted to imagine the smell. In the name-plus-scent condition, the participants also used a toothpick to scratch and sniff the corresponding smell. Following the 20 study-list cards, the participants encountered a set of test instructions that reiterated the nature of the memory test and the three questions that would be asked on each test card [identification of the smell, rating the likelihood that it (or its name) was studied, and indicating the presence or absence of a TOT state for the smell name]. As with the study list, the participants proceeded through the 40-card test list at their own pace, using a toothpick to scratch and smell each sticker and writing their responses on each card using a pen or pencil. Following the first test list, the participants proceeded through the second study list and then its corresponding test list in the same manner as with the first study and test lists.

\section{RESULTS}

An alpha level of $p<.05$ was used to determine statistical significance in all analyses reported here. Although our primary interest in the present study was in odors that could not be identified at test, it is important to first consider how often the participants were able to identify the odors at test. As can be seen in Table 1, identification of the scents at test was fairly difficult, which is consistent with reports in the literature that naming scents is more difficult than naming other types of stimuli (e.g., Cain, 1979; Herz \& Engen, 1996; Schab, 1991; Stevenson et al., 2007). Despite this overall difficulty in naming scents, a 2 (study status: studied vs. nonstudied) $\times 2$ (study condition: name only vs. name plus scent) mixed model ANOVA performed on the proportion of scents identified revealed a main effect of study status such that more test scents were identified overall when either their names or their names and the scents themselves were studied $\left[F(1,66)=163.04, M S_{\mathrm{e}}=0.004, \eta_{\mathrm{p}}^{2}=.71\right]$. Just as identifying word fragments or rapidly flashed and masked stimuli might be considered implicit memory tasks (e.g., Roediger \& McDermott, 1993), so might identifying scents. For this reason, we will refer to the tendency to identify more scents of studied than of nonstudied items as priming, although we do not make any claims regarding the extent to which this priming involves conscious recollection as opposed to implicit memory. This priming effect was larger in the name-plus-scent study condition than in the name-only study condition, as was shown by a significant interaction $\left[F(1,66)=9.49, M S_{\mathrm{e}}=0.004, \eta_{\mathrm{p}}^{2}=.13\right]$. Despite the fact that the degree of priming was greater in the name-plus-scent condition, significant priming was shown in both the name-only condition $[t(33)=2.73, S E=$ $.02, d=0.48]$ and the name-plus-scent condition $[t(33)=$ $11.41, S E=.02, d=1.99]$. The fact that significant priming was shown even in the name-only condition serves as a manipulation check, in that it suggests that there was correspondence between the scents used in the present study and their names. A main effect of study condition revealed that overall identification of test scents was greater in the nameplus-scent condition $\left[F(1,66)=8.29, M S_{\mathrm{e}}=0.01, \eta_{\mathrm{p}}^{2}=\right.$ .11], but Table 1 indicates that this difference was driven largely by the greater degree of priming that occurred in the name-plus-scent condition.

An additional manipulation check came from the recognition ratings given to identified test odors. Although not all of the participants identified odors in both the stud-

Table 1

Mean Proportion of Scents Identified at Test

\begin{tabular}{|c|c|c|c|c|}
\hline \multirow[b]{3}{*}{ Study Condition } & \multicolumn{4}{|c|}{ Study Status } \\
\hline & \multicolumn{2}{|c|}{ Studied } & \multicolumn{2}{|c|}{ Nonstudied } \\
\hline & $M$ & $S D$ & $M$ & $S D$ \\
\hline Name only & .15 & .10 & .04 & .05 \\
\hline Name plus scent & .23 & .10 & .05 & .06 \\
\hline
\end{tabular}


Table 2

Mean Recognition Ratings Given to Unidentified Odors at Test

\begin{tabular}{lccccc}
\hline & \multicolumn{4}{c}{ Study Status } \\
\cline { 2 - 3 } \cline { 5 - 6 } Study Condition & \multicolumn{2}{c}{ Studied } & & \multicolumn{2}{c}{ Nonstudied } \\
\cline { 2 - 3 } \cline { 5 - 6 } & $M$ & $S D$ & & $M$ & $S D$ \\
\hline Name only & 3.59 & 1.94 & & 3.66 & 1.85 \\
Name plus scent & 4.36 & 1.60 & & 3.59 & 1.68 \\
\hline
\end{tabular}

Table 3

Probability of a Tip-of-the-Tongue State for an Unidentified Odor's Name

\begin{tabular}{llllll}
\hline & \multicolumn{3}{c}{ Study Status } \\
\cline { 2 - 3 } \cline { 5 - 6 } Study Condition & \multicolumn{3}{c}{ Studied } & & \multicolumn{2}{c}{ Nonstudied } \\
\cline { 2 - 3 } \cline { 5 - 6 } & $M$ & $S D$ & & $M$ & $S D$ \\
\hline Name only & .47 & .28 & & .49 & .28 \\
Name plus scent & .41 & .25 & & .41 & .22 \\
\hline
\end{tabular}

ied condition and the nonstudied condition, when the participants were able to identify the odors at test, they were also very good at determining whether or not that odor (or its name) had been studied. The participants' ratings were much higher for studied items, regardless of whether the odor itself had been studied $(M=8.93, S D=1.08)$ or only the odor's name had been studied $(M=8.33, S D=$ 2.17), than for nonstudied items in either the name-plusscent condition $(M=1.64, S D=1.98)$ or the name-only condition $(M=2.17, S D=2.62)$. A 2 (study status: studied vs. nonstudied) $\times 2$ (study condition: name only vs. name plus scent) mixed model ANOVA performed on the ratings for identified odors revealed a significant main effect of study status $\left[F(1,46)=228.90, M S_{\mathrm{e}}=4.74, \eta_{\mathrm{p}}^{2}=\right.$ $.83]$ and no other significant effects. Neither the interaction $[F(1,46)=1.64$, n.s. $]$ nor the main effect of study condition $[F(1,46)<1.0]$ was significant.

The data of primary interest are the recognition ratings given to odors that could not be identified at test. In order to use a rather stringent criterion for classifying test odors as unidentified, we classified an odor as unidentified only if the participants gave no identification response at all (i.e., left that line blank on the card). If a person misidentified an odor (by giving an incorrect name), that odor was not included in the pool of items that were classified as unidentified. This meant that 3 participants overall ( 2 in the name-plus-scent condition and 1 in the name-only condition) were lost because they guessed at an odor name for every item. It is worth noting, however, that the same general overall pattern of odor RWI results was shown, regardless of whether misidentified odors were included among the items labeled unidentified.
As is shown in Table 2, an odor RWI effect was shown, but only when the odors themselves had been presented at study. In the name-plus-scent condition, recognition ratings were higher for unidentified odors that were presented at study than for unidentified odors that were not presented at study $[t(31)=4.23, S E=.18, d=0.75]$. In the name-only condition, this pattern did not occur $[t(32)<1]$; in fact, the mean difference was not even in the direction of an odor RWI effect in this condition (as is shown in Table 2). Indeed, a 2 (study status: studied vs. nonstudied) $\times 2$ (study condition: name only vs. name plus scent) mixed model ANOVA performed on the ratings for unidentified odors revealed a significant interaction $\left[F(1,63)=6.44, M S_{\mathrm{e}}=0.86, \eta_{\mathrm{p}}^{2}=.09\right]$, indicating that the ratings difference between studied and nonstudied items in the name-plus-scent condition differed significantly from that shown in the name-only condition. The only other significant effect to emerge from this $2 \times 2$ ANOVA was a significant main effect of study status $\left[F(1,63)=4.60, M S_{\mathrm{e}}=0.86, \eta_{\mathrm{p}}^{2}=.07\right]$, such that higher overall ratings were given to studied than to unstudied odors. However, as can be seen from Table 2, this effect was carried by the name-plus-scent condition. There was no main effect of study condition $(F<1)$. To summarize, odor RWI occurred, but only when the studied scent was reinstated at the time of test; it did not occur when only a scent's name was studied.

We also examined how TOT states for odor names in response to odors varied as a function of experimental condition. It is important to consider the probability of reporting a TOT state for a scent's name, given that a scent could not be identified. These data are presented in Table 3 and were analyzed with a 2 (study status: studied vs. nonstudied) $\times 2$ (study condition: name only vs. name plus scent) mixed model ANOVA. As has been found in prior TOT studies, studying a scent or its name did not increase the likelihood of a TOT state, since there was no main effect of study status $(F<1)$ nor was there an interaction $(F<1)$. There was also no significant main effect of study condition $\left[F(1,64)=1.24, M S_{\mathrm{e}}=0.12\right.$, n.s. $]$.

As in other RWI studies in which TOT states have been examined (Cleary, 2006; Cleary \& Reyes, 2009; Cleary $\&$ Specker, 2007), we examined recognition ratings as a function of TOT state. These data are presented in Table 4. A 2 (study status: studied vs. nonstudied) $\times 2$ (study condition: name only vs. name plus scent) $\times 2$ (TOT status: TOT state vs. non-TOT state) mixed model ANOVA was performed on these recognition ratings. Just as in the prior RWI studies of TOT experiences, the participants in the present study attributed the presence of a TOT state to the

Table 4

Recognition Ratings As a Function of Tip-of-the-Tongue (TOT) State Status for Unidentified Odor Names

\begin{tabular}{|c|c|c|c|c|c|c|c|c|}
\hline \multirow[b]{3}{*}{ Study Condition } & \multicolumn{4}{|c|}{ TOT Present } & \multicolumn{4}{|c|}{ TOT Absent } \\
\hline & \multicolumn{2}{|c|}{ Studied } & \multicolumn{2}{|c|}{ Nonstudied } & \multicolumn{2}{|c|}{ Studied } & \multicolumn{2}{|c|}{ Nonstudied } \\
\hline & $M$ & $S D$ & $M$ & $S D$ & $M$ & $S D$ & $M$ & $S D$ \\
\hline Name only & 4.79 & 2.47 & 4.85 & 2.05 & 2.32 & 1.74 & 2.29 & 1.70 \\
\hline Name plus scent & 5.48 & 2.11 & 4.88 & 2.53 & 3.03 & 1.79 & 2.49 & 1.68 \\
\hline
\end{tabular}


Table 5

Mean Recognition Ratings Across Conditions As a Function of Odor Identifiability

\begin{tabular}{|c|c|c|c|c|c|c|c|c|}
\hline \multirow{3}{*}{$\begin{array}{c}\text { Identifiability } \\
\text { Category }\end{array}$} & \multicolumn{4}{|c|}{ Name Only } & \multicolumn{4}{|c|}{ Name Plus Scent } \\
\hline & \multicolumn{2}{|c|}{$\begin{array}{l}\text { Mean ID } \\
\text { Rate }\end{array}$} & \multicolumn{2}{|c|}{$\begin{array}{c}\text { Recognition } \\
\text { Ratings } \\
\end{array}$} & \multicolumn{2}{|c|}{$\begin{array}{l}\text { Mean ID } \\
\text { Rate }\end{array}$} & \multicolumn{2}{|c|}{$\begin{array}{c}\text { Recognition } \\
\text { Ratings }\end{array}$} \\
\hline & old & $N e w$ & Old & $N e w$ & Old & New & Old & New \\
\hline First $12.5 \%$ & .52 & .17 & 4.57 & 3.99 & .59 & .23 & 4.60 & 3.79 \\
\hline Second $12.5 \%$ & .28 & .05 & 4.02 & 4.30 & .38 & .08 & 4.40 & 4.07 \\
\hline Third 12.5\% & .18 & .03 & 4.33 & 3.16 & .28 & .02 & 3.10 & 4.49 \\
\hline Fourth $12.5 \%$ & .11 & .02 & 4.13 & 3.69 & .22 & .03 & 4.52 & 4.14 \\
\hline Fifth $12.5 \%$ & .06 & .00 & 3.58 & 3.34 & .16 & .02 & 4.86 & 3.20 \\
\hline Sixth $12.5 \%$ & .04 & .02 & 3.31 & 4.03 & .12 & .00 & 4.80 & 2.99 \\
\hline Seventh $12.5 \%$ & .00 & .00 & 2.55 & 4.06 & .07 & .01 & 4.65 & 4.01 \\
\hline Eighth $12.5 \%$ & .00 & .00 & 3.07 & 3.35 & .02 & .00 & 4.59 & 3.70 \\
\hline
\end{tabular}

likelihood that the odor name (or its smell) was studied. This is shown by a main effect of TOT status $[F(1,55)=$ 81.27, $\left.M S_{\mathrm{e}}=0.13, \eta_{\mathrm{p}}^{2}=.60\right]$. This finding adds to a growing body of literature that suggests that the tendency to attribute TOT states to study status is extremely robust, basically occurring whenever recognition ratings are examined as a function of reported TOT states. Thus far, this pattern has been shown when recognition ratings indicate the likelihood that an inaccessible answer to a general knowledge question was studied (Cleary, 2006), that the inaccessible name of a famous scene or landmark was studied (Cleary \& Reyes, 2009), and that the inaccessible name of a celebrity was studied (Cleary \& Specker, 2007). The present study extends this pattern to a situation in which recognition ratings indicate the likelihood that an unidentified odor (or its name) was one that was studied.

Aside from the main effect of TOT status, no other aspects of this ANOVA were significant. However, the interaction between study status and study condition approached significance $\left[F(1,55),=3.36, M S_{\mathrm{e}}=1.49, p=\right.$ $\left..07, \eta_{\mathrm{p}}^{2}=.06\right]$; this likely reflects the fact that an odor RWI effect was only found in the name-plus-scent condition (and not in the name-only condition). Indeed, a 2 (study status) $\times 2$ (TOT status) ANOVA performed on ratings given in the name-only condition revealed that the only significant effect in this condition was the main effect of TOT status $\left[F(1,27)=34.21, M S_{\mathrm{e}}=5.18, \eta_{\mathrm{p}}^{2}=.56\right]$ (all other $F \mathrm{~s}<1$ ). However, in the name-plus-scent condition, the same analysis revealed a significant main effect of study status $\left[F(1,28)=12.21, M S_{\mathrm{e}}=0.78, \eta_{\mathrm{p}}^{2}=.30\right]$, such that higher ratings were given to unidentified test odors that were studied than to unidentified test odors that were not studied. The only other significant effect to emerge from this analysis in the name-plus-scent condition was the main effect of TOT status $[F(1,28)=50.06$, $\left.M S_{\mathrm{e}}=3.39, \eta_{\mathrm{p}}^{2}=.64\right]$. The interaction was not significant $(F<1)$.

Finally, as is shown in Table 1, the baseline probability of identifying an odor from its sticker was approximately .04 or .05 (as was shown in the mean identification probabilities for nonstudied items). Although this low baseline probability of identification is consistent with work suggesting that identifying odors is generally very difficult for people (e.g., Cain, 1979; Herz \& Engen, 1996; Stevenson et al., 2007), this low baseline rate of identification might cause some to be concerned that the only reason that no odor RWI effect was shown in the name-only condition was that the participants never had these particular scent-name associations in memory to begin with. Three aspects of the present study suggest otherwise. First, if there had been no correspondence between the odors and their names in memory prior to the experiment, priming should not have occurred in the name-only condition. However, as is shown in Table 1, priming occurred in this condition; it was easier for the participants to identify an odor at test when primed with the name of that odor at study. Second, we examined recognition ratings for unidentified odors as a function of how identifiable those odors were, on average. Specifically, we divided the 80 odors into eight groups of 10 according to the identification rate for each odor. The 10 odors with the highest identification rates were in the first $12.5 \%$, the 10 odors with the next highest identification rates were in the next $12.5 \%$, and so on for the eight groups; odors in the eighth group were those with the lowest overall probability of being identified (see Table 5).

With these data, we first performed a 2 (study status: studied vs. nonstudied) $\times 2$ (study condition: name only vs. name plus scent) $\times 8$ (odor identifiability category: 1st, 2nd, 3rd, 4th, 5th, 6th, 7th, or 8th identification category) mixed items ANOVA (where items were treated as participants) on ratings given to unidentified odors. This analysis revealed a significant three-way interaction $\left[F(1,7)=3.91, M S_{\mathrm{e}}=1.60, \eta_{\mathrm{p}}^{2}=.28\right]$. As can be seen in Table 5, this interaction was such that the presence or absence of the odor RWI effect differed across the odor identification categories depending on whether the study condition was the name-only or the name-plus-scent condition at study. For the name-plus-scent condition, a 2 (study status) $\times 8$ (odor identifiability category) mixed items ANOVA performed on ratings given to unidentified odors revealed a significant main effect of study status $\left[F(1,72)=8.72, M S_{\mathrm{e}}=1.89, \eta_{\mathrm{p}}^{2}=.11\right]$, such that across the different odor identifiability categories, higher overall ratings were given to odors that were studied than to odors that were not studied. There was no main effect of odor identifiability category $(F<1)$. However, the two-way interaction was significant $\left[F(1,7)=2.55, M S_{\mathrm{e}}=1.89\right.$, $\left.\eta_{\mathrm{p}}^{2}=.20\right]$; as can be seen in Table 5, this interaction was 
such that the ratings trend (of higher ratings for studied than for nonstudied odors) reversed itself in the third identifiability category. The same $2 \times 2$ ANOVA revealed no significant effects for the name-only condition. In short, not only did study status not have an effect across identification categories in the name-only condition, but the effects of study status in the name-plus-scent condition differed significantly from those in the name-only condition (as is shown by the significant three-way interaction).

To summarize, the overall pattern of results suggests that the lack of an odor RWI effect in the name-only condition is not easily attributable to the participants' simply never having known the scents prior to the experiment: The effect (or lack thereof) did not vary as a function of how identifiable the scents were in this condition, this lack of an effect in the name-only condition across identifiability categories significantly differed from the effect found in the name-plus-scent condition (as was shown by a significant three-way interaction), and this overall pattern across identifiability categories was found despite the fact that studying an odor's name by itself significantly increased the likelihood of identifying the odor at test in the name-only condition, which suggests that there was some degree of correspondence between the names and their odors in the present study.

\section{DISCUSSION}

\section{The Odor RWI Effect}

The present study extended the RWI effect (e.g., Arndt et al., 2008; Cleary, 2002, 2006; Cleary \& Greene, 2000, 2001; Cleary et al., 2004; Cleary \& Reyes, 2009; Cleary \& Specker, 2007; Kostic \& Cleary, 2009; Langley et al., 2008; Peynircioğlu, 1990) to odors that could not be identified at test. Despite being unable to identify odors from blank scratch-and-sniff stickers on a recognition test, the participants were able to discriminate between odors that had been presented at study and odors that had not been presented at study. This odor RWI effect only occurred in the condition in which the studied test odors themselves had actually been smelled at study. It did not occur when only the odor names had been studied; in the absence of odor identification, the participants did not discriminate odors whose names were studied from odors whose names were not studied. This pattern of findings suggests that the odor RWI effect reported here is an episodic perceptually driven phenomenon.

Our pattern of findings is roughly consistent with recent work by Jönsson et al. (2005), who found that FOKs for odors were correlated with the familiarity of the odors. From this, Jönsson et al. argued that the cue familiarity (of the odor itself) drove the FOKs, as has been shown with other types of stimuli (Metcalfe, Schwartz, \& Joaquim, 1993). Although RWI differs from FOK (whereas RWI involves a retrospective memory judgment, FOKs involve prospective judgments), our findings are consistent with those of Jönsson et al. insofar as we show that the sense of retrospective recognition for unidentified odors is driven primarily by reinstated perceptual characteristics of the odors. That is, familiarization of the odor itself through prior presentation in the experiment is what appears to produce odor RWI.

The present findings contribute to a growing body of literature suggesting that whereas some forms of RWI involve preexisting semantic knowledge (e.g., Cleary, 2006; Cleary \& Reyes, 2009; Cleary \& Specker, 2007), others involve episode-specific perceptual representations (e.g., Arndt et al., 2008; Langley et al., 2008). Our results suggest that odor RWI is of the latter type, requiring a reinstatement of the perceptual aspects of the studied odor at the time of test. In this regard, odor RWI behaves more like RWI of rapidly flashed, masked line drawings of common objects (Langley et al., 2008), or nonwords (Arndt et al., 2008), which have been shown to require reinstatement of the perceptual aspects of the studied episodes to occur.

That odor RWI may be one of the forms of RWI that requires a reinstatement of episode-specific perceptual information is consistent with evidence suggesting that the link between an odor and its name in memory may be weaker than the link between a visual image and its name (e.g., Stevenson \& Case, 2005; Stevenson et al., 2007). Researchers have long known that odors are more difficult to name than visual images or other types of stimuli (e.g., Herz \& Engen, 1996; Schab, 1991). Stevenson et al. report findings suggesting that the reverse is also true: It is more difficult to imagine an odor (e.g., the smell of strawberry) in response to its name than to imagine what the source of the odor looks like (e.g., a visual image of a strawberry) in response to its name. The present results are consistent with the idea that odors and their names are not particularly well connected in semantic memory. However, it remains possible that odors are not uniquely weakly connected to their names but, rather, are weakly connected to all identifying information about their source (e.g., Jönsson et al., 2005).

\section{Implications for TOT Research}

Despite prior evidence that TOT states for odor names differ from TOT states for other types of information (Lawless \& Engen, 1977), just as in studies of RWI for other types of information, the participants in the present study attributed the feeling of being in a TOT state for an odor's name to the likelihood that the odor (or its name) had been studied. In this regard, the present study contributes to a growing number of studies showing that this TOT-attribution effect (Cleary, 2006; Cleary \& Reyes, 2009; Cleary \& Specker, 2007) is extremely robust. The TOT-attribution effect might be considered to be the reverse of the usual relationship between attribution and TOTs. Whereas many researchers have suggested that TOTs can be based on attributions (see Schwartz, 2002, for a review), with the TOT-attribution effect, the TOTs themselves are what are being attributed. Specifically, participants attribute the presence or absence of a TOT state to the likelihood that the unretrievable item was studied. Thus far, the TOT-attribution effect has been shown to occur when participants rate the likelihood that the answer to a general knowledge question was studied (Cleary, 2006), that a celebrity's name was studied (Cleary $\&$ Specker, 2007), and that the name of a famous scene or 
landmark was studied (Cleary \& Reyes, 2009). The finding that this TOT-attribution effect occurs when the participants rate the likelihood that an odor (or its name) was studied suggests that it is a highly generalizable effect, occurring even for TOT states that are thought to differ from standard types of TOT states.

The TOT-attribution effect is interesting because it suggests that participants find TOT states to be indicative of prior study of a momentarily inaccessible item, even though in most cases, TOT states are not indicative of this (as the likelihood of a TOT state itself does not increase for studied items relative to nonstudied items). The fact that participants believe TOT states to be indicative of an inaccessible item's past appearance at study suggests that the feeling of being in a TOT state and the feeling of familiarity that allows for the recognition of prior experience may subjectively be very similar. That is, the feeling of being in a TOT state may feel like the feeling of familiarity related to a past episode.

In addition, consistent with prior studies (Cleary, 2006; Cleary \& Reyes, 2009; Cleary \& Specker, 2007), the present study demonstrated that studying a scent's name (with or without the corresponding scent itself) did not lead to an increase in the likelihood of a reported TOT state. This is especially interesting with regard to the comparison between the name-only condition and the name-plus-scent condition, because it suggests that whereas odor RWI itself may be driven by the perceptual familiarity of the odors, TOT states for odor names are not driven by the perceptual familiarity of the odors. If TOTs were based on the perceptual familiarity of the odors, one would expect to find a greater likelihood of a reported TOT state when the odor itself was familiarized through prior presentation than when it was not. This is not what was found in the present study; the likelihood of a reported TOT state did not differ significantly across conditions, nor was there even a trend in the direction of a greater likelihood of TOTs for familiarized odors. This suggests that although the familiarity of the odor itself may drive odor RWI, what drives TOTs for odor names is a type of information different from what drives the familiarity of the odor itself. This is somewhat consistent with the findings of Jönsson et al. (2005).

\section{Summary, Conclusions, and Future Directions}

In summary, the present study demonstrated an empirical odor RWI effect and demonstrated that this effect is not among the types of RWI that occur when only names are studied and their referents are presented at test. Instead, the odor RWI effect reported here occurred only when the odor at test was a reinstatement of an odor that was studied. Despite this, both conditions (the name-only and name-plus-scent conditions) showed the TOT-attribution effect that has been shown in prior studies of RWI.

In providing converging evidence for the idea that odors and their names are weakly linked in semantic memory, the present results contribute to a growing paradox in the literature on odor memory. On one hand, there is the aforementioned evidence that odors and their names are weakly linked in semantic memory (e.g., Schab, 1991; Stevenson $\&$ Case, 2005; Stevenson et al., 2007). Odors are diffi- cult to name; they are difficult to imagine in response to names; they do not tend to elicit partial information about their names during TOT states; and as shown in the present study, they do not show the laboratory-based RWI effect unless the actual odors themselves (and not just the odor names) were studied. On the other hand, there is what has come to be known as the "Proust effect," which is the idea that odors are better cues for autobiographical memories than are other sensory cues (e.g., Chu \& Downes, 2000). Thus, although odors appear to be weakly linked to their names in semantic memory, they may be strongly linked to certain types of episodic memories, possibly most likely when an odor cue uniquely specifies a particular past experience (e.g., Nairne, 2002), such as when a mixture of odors unique to a specific museum is used to cue memory for a prior visit to that museum (Aggleton \& Waskett, 1999).

In light of this apparent paradox, the present study raises the question of whether the ability to recognize odors that cannot be identified, or the "tip-of-the-nose" effect (e.g., Lawless \& Engen, 1977; Schab, 1991), is due to a mere feeling of familiarity with an unidentifiable odor or whether it is an episodic recollection of a prior occurrence with that odor in the face of an inability to identify the odor itself. Future research might aim to determine whether unidentifiable but highly familiar odors (e.g., strawberry, leather) are effective cues for episodic or autobiographical recollections, despite being unnameable, or whether unidentifiable familiar odors are poor cues for episodic recollections but effective triggers of feelings of familiarity.

\section{AUTHOR NOTE}

This project was funded by NSF Grants BCS-0638486 to A.M.C. and SES-0552876 REU Grant to Edward L. DeLosh. The data reported here were collected as part of K.E.K.'s research project for the 2008 Summer REU Program on Mind and Brain at Colorado State University. Correspondence concerning this article should be addressed to A. M. Cleary, Department of Psychology, Colorado State University, 1876 Campus Delivery, Fort Collins, CO 80523-1876 (e-mail: anne.cleary@) colostate.edu).

\section{REFERENCES}

Aggleton, J. P., \& Waskett, L. (1999). The ability of odours to serve as state-dependent cues for real-world memories: Can Viking smells aid the recall of Viking experiences? British Journal of Psychology, 90, 1-7.

ARndT, J., LeE, K., \& Flora, D. B. (2008). Recognition without identification for words, pseudowords and nonwords. Journal of Memory \& Language, 59, 346-360.

Brown, A. S. (1991). A review of the tip-of-the-tongue experience. Psychological Bulletin, 109, 204-223.

Burton, A. M., Bruce, V., \& Hancock, P. J. B. (1999). From pixels to people: A model of familiar face recognition. Cognitive Science, 23, $1-31$.

CAIN, W. S. (1979). To know with the nose: Keys to odor identification. Science, 203, 467-470.

Cain, W. S., de Wijk, R., Lulejian, C., Schiet, F., \& See, L.-C. (1998). Odor identification: Perceptual and semantic dimensions. Chemical Senses, 23, 309-326.

Chu, S., \& Downes, J. J. (2000). Odour-evoked autobiographical memories: Psychological investigations of Proustian phenomena. Chemical Senses, 25, 111-116.

Cleary, A. M. (2002). Recognition with and without identification: Dissociative effects of meaningful encoding. Memory \& Cognition, 30, 758-767. 
Cleary, A. M. (2006). Relating familiarity-based recognition and the tip-of-the-tongue phenomenon: Detecting a word's recency in the absence of access to the word. Memory \& Cognition, 34, 804-816.

Cleary, A. M., \& Greene, R. L. (2000). Recognition without identification. Journal of Experimental Psychology: Learning, Memory, \& Cognition, 26, 1063-1069.

Cleary, A. M., \& Greene, R. L. (2001). Memory for unidentified items: Evidence for the use of letter information in familiarity processes. Memory \& Cognition, 29, 540-545.

Cleary, A. M., \& Greene, R. L. (2004). True and false memory in the absence of perceptual identification. Memory, 12, 231-236.

Cleary, A. M., \& Greene, R. L. (2005). Recognition without perceptual identification: A measure of familiarity? Quarterly Journal of Experimental Psychology, 58A, 1143-1152.

Cleary, A. M., Langley, M. M., \& SeIler, K. R. (2004). Recognition without picture identification: Geons as components of the pictorial memory trace. Psychonomic Bulletin \& Review, 11, 903-908.

Cleary, A. M., \& Reyes, N. L. (2009). Scene recognition without identification. Acta Psychologica, 131, 53-62.

Cleary, A. M., \& Specker, L. E. (2007). Recognition without face identification. Memory \& Cognition, 35, 1610-1619.

Cleary, A. M., Winfield, M. M., \& Kostic, B. (2007). Auditory recognition without identification. Memory \& Cognition, 35, 1869-1877.

Djordjevic, J., Lundstrom, J. N., Clément, F., Boyle, J. A., Pouliot, S., \& Jones-Gotman, M. (2008). A rose by any other name: Would it smell as sweet? Journal of Neurophysiology, 99, 386-393.

Djordjevic, J., Zatorre, R. J., Petrides, M., \& Jones-Gotman, M. (2004). The mind's nose: Effects of odor and visual imagery on odor detection. Psychological Science, 15, 143-148.

Gollan, T. H., \& Brown, A. S. (2006). From tip-of-the-tongue (TOT) data to theoretical implications in two steps: When more TOTs means better retrieval. Journal of Experimental Psychology: General, 135, 462-483.

Herz, R. S. (2003). The effect of verbal context on olfactory perception. Journal of Experimental Psychology: General, 132, 595-606.

Herz, R. S., \& Engen, T. (1996). Odor memory: Review and analysis. Psychonomic Bulletin \& Review, 3, 300-313.

HERZ, R. S., \& VON CLEF, J. (2001). The influence of verbal labeling on the perception of odors: Evidence for olfactory illusions? Perception, 30, 381-391.
Jönsson, F. U., \& Olsson, M. J. (2003). Olfactory metacognition. Chemical Senses, 28, 651-658.

Jönsson, F. U., TCHeKhova, A., LÖNNER, P., \& Olsson, M. J. (2005). A metamemory perspective on odor naming and identification. Chemical Senses, 30, 353-365.

Kostic, B., \& Cleary, A. M. (2009). Song recognition without identification: When people cannot "name that tune" but can recognize it as familiar. Journal of Experimental Psychology: General, 138, 146-159.

Langley, M. M., Cleary, A. M., Kostic, B. N., \& Woods, J. A. (2008). Picture recognition without picture identification: A method for assessing the role of perceptual information in familiarity-based picture recognition. Acta Psychologica, 127, 103-113.

LAWLess, H., \& EngEN, T. (1977). Associations to odors: Interference, mnemonics, and verbal labeling. Journal of Experimental Psychology: Human Learning \& Memory, 3, 52-59.

Metcalfe, J., Schwartz, B. L., \& Joaquim, S. G. (1993). The cuefamiliarity heuristic in metacognition. Journal of Experimental Psychology: Learning, Memory, \& Cognition, 19, 851-861.

NaIRne, J. S. (2002). The myth of the encoding-retrieval match. Memory, 10, 389-395.

PeYNiRCIOĞLU, Z. F. (1990). A feeling-of-recognition without identification. Journal of Memory \& Language, 29, 493-500.

Rastle, K. G., \& Burke, D. M. (1996). Priming the tip of the tongue: Effects of prior processing on word retrieval in young and older adults. Journal of Memory \& Language, 35, 586-605.

RoEdiger, H. L., III, \& McDermott, K. B. (1993). Implicit memory in normal human subjects. In F. Boller \& J. Grafman (Eds.), Handbook of neuropsychology (Vol. 8, pp. 63-131). Amsterdam: Elsevier.

Schab, F. R. (1991). Odor memory: Taking stock. Psychological Bulletin, 109, 242-251.

Schwartz, B. L. (2001). The relation of tip-of-the-tongue states and retrieval time. Memory \& Cognition, 29, 117-126.

Schwartz, B. L. (2002). Tip-of-the-tongue states: Phenomenology, mechanism, and lexical retrieval. Mahwah, $\mathrm{NJ}$ : Erlbaum.

Secundo, L., \& Sobel, N. (2006). The influence of smelling coffee on olfactory habituation [Abstract]. Chemical Senses, 31, A52.

Stevenson, R. J., \& Case, T. I. (2005). Olfactory imagery: A review. Psychonomic Bulletin \& Review, 12, 244-264.

Stevenson, R. J., Case, T. I., \& Mahmut, M. (2007). Difficulty in evoking odor images: The role of odor naming. Memory \& Cognition, 35, 578-589.

\section{Names of the Stimulus Scents}

\begin{tabular}{llll}
\hline MILDEW & NUTMEG & LIME & LEMON \\
MOTHBALL & JASMINE & SWEET POTATOES & EUCALYPTUS \\
WET DIRT & HAZELNUT & JUNIPER BERRY & CEDAR \\
NATURAL GAS & GARLIC & GRAPE & ROOT BEER \\
CUCUMBER & CLOVE & COCONUT & HONEYSUCKLE \\
ASHTRAY & CINNAMON & CHERRY & POPCORN \\
WINE & BLACK PEPPER & APPLE & PEANUT BUTTER \\
RACING FUEL & BUTTERSCOTCH & BLUEBERRY & MARSHMALLOW \\
SUNTAN OIL & BASIL & BANANA & MAPLE \\
LEATHER & ONION & ALMOND & LICORICE \\
CIGAR & DILL PICKLE & VIOLET & HONEY \\
BUBBLEGUM & BROCCOLI & TULIP & GINGERBREAD \\
CIDER & STRAWBERRY & ROSE & FISH \\
BABY POWDER & RASPBERRY & PINE & COLA \\
ROAST BEEF & BURNT RUBBER & LILY & MONEY \\
VANILLA & PINEAPPLE & LILAC & COFFEE \\
SPEARMINT & PEAR & LAWN & CHILI \\
CAMPFIRE SMOKE & PEACH & LAVENDER & CHOCOLATE \\
ROSEMARY & ORANGE & HYACINTH & CARAMEL \\
PEPPERMINT & MANGO & GARDENIA & BAILEY'S IRISH CREAM \\
\hline
\end{tabular}

